\title{
A PRÓCLISE EM SENTENÇAS INFINITIVAS PREPOSICIONADAS EM PB
}

\author{
PROCLISIS IN INFINITIVE PREPOSITIONAL SENTENCES IN BP
}

Marco Antonio Martins

Docente do Programa de Pós-graduação em Linguística e do Departamento de Língua

e Literatura Vernáculas da Universidade Federal de Santa Catarina

marco.martins@ufsc.br

Geison Luca de Sena Pereira

Mestre em Estudos da Linguagem pela Universidade Federal do Rio Grande do Norte geison_pereira@outlook.com

Resumo: Apresentamos, neste artigo, uma análise formal para a colocação de clíticos em sentenças infinitivas preposicionadas no português brasileiro (PB). A análise se baseia no trabalho desenvolvido por Sena Pereira (2015) que aborda a colocação de clíticos nesse contexto na escrita brasileira dos séculos XIX e XX. Nossa proposta é que preposições que ocupam o núcleo de CP motivam mudanças nos valores atribuídos aos traços-phi e aos traços-V fortes nas categorias funcionais COMP, Tempo e Pessoa no PB. Defendemos que em tal configuração a próclise em $\mathrm{PB}$ é derivada do movimento do verbo para a categoria funcional Tempo em que há a associação de traços [+V] e traços [+AGR].3

Palavras-chave: Próclise; Sentenças infinitivas preposicionadas; Traços-V; TraçosAGR.

Abstract: We present in this paper a formal analysis of the placement of clitics in infinitive prepositional sentences in Brazilian Portuguese. The analysis is based on the work of Sena Pereira (2015), which discusses the placement of clitics in this context in the Brazilian writing of the nineteenth and twentieth centuries. Our proposal is that prepositions occupying the core of $\mathrm{CP}$ motivate changes in the values attributed to phi features and strong V features in functional categories COMP, Tense and Person in Brazilian Portuguese. We argue that, in such configuration, proclisis in Brazilian Portuguese is derived from verbal movement to the functional category Tense where the combination of $[+\mathrm{V}]$ and $[+\mathrm{AGR}]$ features are present.

Keywords: Proclisis; Infinitive prepositional sentences; V features; AGR features. 


\section{Introdução}

O estudo da ordenação de constituintes nas línguas românicas tem ocupado um lugar de destaque em sintaxe diacrônica. Muitos são aqueles estudos relacionados à posição e à colocação de clíticos nas gramáticas do português: Martins (1994), Galves, Brito e Paixão de Sousa (2005) sobre o Português arcaico (PA) e no Português clássico (PC); Mateus et al. (2003) e Martins (2013) sobre o Português europeu (PE); Pagotto (1992), Shei (2003), Martins (2009; 2012), Carneiro (2005), Carneiro e Galves (2010) sobre o Português Brasileiro (PB $)^{1}$. Contudo, a maioria desses estudos abordam a colocação dos pronomes pessoais clíticos em todos os contextos sintáticos. Considerando a necessidade de uma análise para a colocação de clíticos num contexto específico que apresenta padrões diferenciados na história do português, apresentamos aqui uma proposta de análise formal para os padrões de colocação dos pronomes pessoais clíticos em um contexto bastante específico: sentenças infinitivas preposicionadas na escrita brasileira dos séculos XIX e XX. Seguimos a análise de Sena Pereira (2015) que se baseia na articulação de duas propostas teóricas: (i) a de Galves $(2000 ; 2001)$ para a qual a colocação de clíticos está associada à relação existente entre os traços-phi e os traços V-fortes nas gramáticas do português; e (ii) a de Magro (2005) acerca dos diferentes estatutos categoriais que as preposições podem assumir na derivação das sentenças em português.

A análise está baseada nos pressupostos do programa minimalista da teoria gerativa (CHOMSKY, 1995, 1998) visto que um dos fatores importantes para a explicação da derivação da próclise e da ênclise em sentenças infinitivas preposicionadas nas gramáticas do português é a combinação de traços-phi a traços V-fortes nas gramáticas do PC, do PE e do PB. A proposta é a de que a mudança do estatuto categorial das preposições afeta a valoração dos traços-phi e V-fortes nas categorias COMP, Tempo e Pessoa na gramática do PB e essa modificação acarreta a mudança nos padrões de colocação dos pronomes pessoais clíticos em sentenças infinitivas preposicionadas.

O artigo está assim organizado: na Seção 2, sumarizamos os principais resultados de estudos que tratam da colocação de clíticos em sentenças infinitivas nas gramáticas do português; na Seção 3, apresentamos as duas propostas teóricas que foram articuladas

\footnotetext{
${ }^{1}$ Não faremos aqui uma retomada dos muitos estudos sobre o fenômeno da colocação dos pronomes pessoais clíticos no português.
} 
para o desenvolvimento da análise; na Seção 4, apresentamos uma análise para a colocação de clíticos em sentenças infinitivas preposicionadas em PB.

\section{A colocação de pronomes clíticos em sentenças infinitivas em português}

Para situar a análise que propomos, sumarizamos nesta seção, muito brevemente, resultados de trabalhos referentes à colocação de clíticos em sentenças infinitivas preposicionadas nas gramáticas do português: Martins (1994) para o Português Antigo; Magro (2005) e Martins (2013) para o PE; e Schei (2003) para o PB.

Martins (1994) analisa a colocação de clíticos em sentenças com verbo no infinitivo extraídas de corpus formado por documentos notórios editados pela autora. De acordo com a análise da autora, a colocação de clítico em oração com predicador na forma infinitiva precedido pelas preposições de, pera e $a$ apresenta diferentes padrões de ordenação em textos dos séculos XIII a XIV: (a) há próclise majoritária nas sentenças com verbos precedidos pela preposição de; (b) há variação livre em sentenças com a preposição pera; e (c) há ênclise categórica nas sentenças com a preposição $a$. Não obstante, nas palavras da autora, a colocação de clíticos em verbos regidos por essas preposições "virá a uniformizar-se posteriormente, passando a colocação dos pronomes complemento átonos a ser a mesma independentemente da preposição que introduz o infinitivo”. (MARTINS, 1994, p. 109). Os dados abaixo ilustram os padrões descritos acima com as preposições de, pera e $a$ :

(1) que nẽgũu nõ seya ousado de LJ fazer mal.

(2) noméé em as uída pessoa que seía clérigo mays chegado do línnhagẽ pera á dita sucessom e pera tragalLA assy cõmo de suso dito hé.

(3) e obrigo-me per todos meus bẽes a cõpriLAS e a gaurdalas.

(MARTINS, 1994, p. 110-120)

A análise de Martins (1994) mostra que as sentenças infinitivas com verbos precedidos por preposição constituem um ambiente de variação já no período que compre- 
ende os séculos XIII e XVI. Contudo, vale ressaltar que, nos dados em que o verbo é precedido pelas proposições pera e $a$, a colocação de clítico passa ser proclítica a partir do século XIV, juntando-se ao padrão instanciado nas sentenças com verbos precedidos pela preposição de. Apesar de considerar apenas a colocação de clíticos em sentenças infinitivas com verbos precedidos pelas preposições pera, de e $a$, a análise de Martins (1994) mostrou ainda que as sentenças infinitivas com verbo precedidos por preposição constituem um ambiente de variação durante os séculos XIII e XIV e que, a partir do século XIV, há uma forte tendência à anteposição do pronome pessoal clítico.

No que se refere ao PE, Magro (2005) apresenta uma analisa de dados de fala oriundos do Corpus Dialectal com Anotação Sintáctica (CORDIAL-SIN). De acordo com autora, no contexto das infinitivas preposicionadas em PE, ocorre variação na colocação de clíticos e essa variação está diretamente ligada ao tipo de preposição que antecede o verbo no infinitivo. Nos casos de oração com verbo precedido pelas preposições $a$ e em, a ênclise é quase categórica e alcança percentuais de $75 \%$ e $95 \%$. Já em sentenças com verbos precedidos pelas preposições de, para, por e sem, a próclise é o padrão, alcançando percentuais de $90,2 \%, 92,8 \%$, 100\% e $83,3 \%$. Os altos índices de próclise no estudo de Magro (2005) no PE podem ser justificados pela ocorrência de sentenças com infinitivos flexionados antecedidos por preposições que favoreçam a anteposição do clítico, pois de acordo com Martins (2013), todas as preposições, exceto $a$ e com, favorecem a ênclise em PE.

Sobre dados do PB, Schei (2003) analisa e descreve a colocação de clíticos em romances escritos por autores brasileiros nascidos no século XX. Os resultados da autora apontam para o fato de este contexto também ser um ambiente de variação próclise $(\mathrm{clV}) /$ ênclise $(\mathrm{Vcl})$. Contudo, mesmo com taxas de ênclise que alcançam 53\% em textos de um dos autores analisados, o percentual de ocorrência de próclise é mais elevado na maioria dos autores, alcançando 77\% e 97\%. Schei (2003) destaca o comportamento diferenciado do pronome clítico acusativo de terceira pessoa O/A. Nos textos da maioria dos autores, esse clítico aparece enclítico, exceto em textos de um dos autores que preferencialmente coloca o clítico anteposto ao verbo infinitivo. Retirados da amostra o clítico acusativo de terceira pessoa, tornou-se evidente na análise de Schei a predominância da colocação proclítica em sentenças infinitivas com verbo precedido por preposição no PB, com percentuais na média de $93 \%$. 
Apresentados alguns resultados de estudos sobre os padrões de colocação dos pronomes pessoais clíticos em português em sentenças infinitivas preposicionadas nas gramáticas do português, passemos à revisão de duas propostas teóricas que estão na base da análise que propomos neste artigo para a derivação da próclise nesse contexto em PB.

\section{Revisitando as propostas de Galves (2000; 2001) e Magro (2005)}

Como já dito, a análise que propomos é resultado da articulação teórica da proposta de Galves $(2000 ; 2001)$ para a colocação de clíticos em sentenças finitas nas gramáticas do português e a proposta de Magro (2005) sobre o estatuto categorial das preposições. Detalharemos essas duas propostas nas subseções que seguem.

\subsection{A proposta de Galves (2000; 2001$)$ : traços-phi, traços-V e as categorias COMP, Tempo e Pessoa nas gramáticas do português}

A proposta de Galves $(2000 ; 2001)$ busca explicar como a próclise em sentenças finitas é derivada nas gramáticas do português. A proposta é baseada em pressupostos do Programa Minimalista da gramática gerativa e trabalha com a hipótese de que dois parâmetros específicos diferem nos sistemas de concordância das línguas. Esses parâmetros são relativos à associação de (1) traços-phi (AGR) às diversas categorias funcionais como COMP, Tempo e Pessoa e de (2) traços-V fortes aos traços-phi. Galves assume que esses são os processos gramaticais que fazem com que a colocação de clíticos em PB seja majoritariamente proclítica em determinados contextos.

Galves parte do pressuposto de que AGR é, antes de mais nada, um conjunto de traços-phi:

Entre a noção puramente relacional e a definição de uma categoria, sempre que uma relação de concordância se estabelece, existe uma terceira via, já subjacente nos modelos anteriores, mas que parece particularmente pertinente explicitar no quadro minimalista. Consiste em definir AGR, antes de mais nada, como um conjunto de traços- $\varphi$. Esses traços- $\varphi$ podem 
constituir o núcleo de uma categoria funcional independente ou, ao contrário estar associados a uma outra categoria funcional. (GALVES, 2001, p. 222)

A proposta de Galves (2000; 2001) está baseada inicialmente em três hipóteses: (a) os clíticos pronominais são feixes de traços-phi e assim correspondem à realização de AGR; (b) os clíticos pronominais podem ser gerados em posição argumental e, em seguida, sofrer adjunção ao verbo, acorrendo assim a colocação proclítica; e (c) em ênclise, o clítico é morfologicamente associado ao verbo, formando uma unidade morfológica com seu hospedeiro. Essas hipóteses apontam para duas assunções interessantes:

I. Ao considerar que os clíticos pronominais são feixes de traços-phi, relacionam-se esses elementos diretamente à ocorrência de AGR nas categorias funcionais. Essa análise se opõe à proposta de que os clíticos são determinantes. Segundo Galves, conceber os clíticos pronominais como determinantes é problemático, pois os determinantes são categorias associadas à referência, logo a ausência de referência característica de alguns clíticos não poderia ser explicada. Com isso, Galves (2000; 2001), baseada em Rizzi (1990), assume que os clíticos são feixes de traços-phi.

II. Próclise e ênclise possuem naturezas distintas, pois a próclise é vista como o resultado da adjunção do clítico ao verbo após a partícula átona ser gerada em posição argumental, enquanto a ênclise, por outro lado, forma uma unidade morfológica com o verbo, ou seja, nesse caso, o clítico é visto como uma partícula de concordância que faz parte da morfologia verbal.

Dada a natureza distinta dos clíticos pronominais em próclise ou ênclise, basta-nos assumir com Galves quais são os fatores que legitimam e motivam cada uma dessas colocações. Para a autora, a colocação enclítica ou proclítica depende da maneira que os parâmetros destacados anteriormente (a associação de traços-phi às categorias funcionais e a associação de traços-phi a traços- $\mathrm{V}$ fortes) se realizam na derivação e, também, da relação Especificador/Núcleo estabelecida por um dado elemento para aonde o verbo é deslocado.

A relação Especificador/Núcleo estabelecida em uma categoria ocorre devido à associação de traços-phi. Quando ocorre compatibilidade, os traços-phi ficam na posição de Especificador da categoria a qual estão vinculados, exigindo que um elemento faça a 
checagem desse traço, pois os traços-phi não são interpretáveis nos módulos de interface. De acordo com Galves (2000; 2001), essa relação Especificador/Núcleo é incompatível com a ocorrência de ênclise por causa da ocorrência de traços-phi na categoria que hospeda o verbo. A incompatibilidade entre a ênclise e a relação Especificador/Núcleo é assim explicada por Galves:

\begin{abstract}
A propriedade comum à topicalização e às orações infinitivas é que o núcleo que contém o verbo e o clítico não entra em nenhuma relação de Especificador/Núcleo. Em orações infinitivas, não há sujeito lexical para concordar e, em construções topicalizadas, [...], o tópico está fora de CP. Se acreditarmos nessa similaridade entre esses dois casos de ênclise, podemos formular a seguinte generalização: a ênclise é incompatível com a existência de uma relação Especificador-Núcleo que envolve o núcleo que contém o clítico. (GALVES, 2001, p. 251).
\end{abstract}

Galves assume assim uma generalização a partir da observação de dois contextos em que a colocação de clítico se dá obrigatoriamente de forma enclítica. Essa generalização consiste na incompatibilidade da ênclise com a relação de Especificador/Núcleo; ou seja, se o pronome clítico estiver junto a um verbo em uma categoria com a necessidade de preencher a posição de Especificador com algum elemento, a ênclise não é lícita. Segundo Galves, o fator que possibilita a existência da relação Especificador/Núcleo é a associação de traços-V fortes aos traços-phi de AGR. Com isso, propõe que a colocação proclítica ou enclítica ocorre, basicamente, a partir das seguintes regras: (1) a próclise ocorrerá se o clítico for adjungido a um verbo localizado em um núcleo dotado de traçosARG e (2) a ênclise ocorrerá se o verbo, em Spell-out, não conter ARG.

Além da natureza dos traços-phi e das condições para ocorrência de próclise e ênclise, Galves $(2000 ; 2001)$ assume a existência de uma categoria funcional existente entre CP e TP que possui, assim como outras categorias funcionais, traços [+ interpretáveis]: Pessoa $^{2}$. A autora prevê também que a essa categoria Pessoa estão associados traços-phi [-interpretáveis] que devem ser checados por meio do movimento de um elemento que possua traços-phi.

\footnotetext{
2 Não apresentaremos aqui, por fugir à proposta do artigo a ontologia por trás da postulação dessa categoria na proposta de Galves (2000; 2001). Para isso remetemos o leitor aos textos de Galves.
} 
Considerando essas condições específicas para a ocorrência de próclise ou ênclise e a existência de uma categoria funcional Pessoa entre CP e TP, as diferenças atestadas na colocação dos pronomes clíticos nas gramáticas do português devem ocorrer devido a diferenças nos valores atribuídos aos traços- $\mathrm{V}$, responsáveis pela movimentação do verbo, e os traços-AGR nas categorias funcionais COMP, Tempo e Pessoa. Os valores atribuídos a esses traços em COMP, Tempo e Pessoa em PC, PE e PB estão especificados no esquema abaixo retirado de Galves (2001, p. 253):
PC: COMP: $[+\mathrm{V}] /[-\mathrm{AGR}]$
PE: COMP: $[-\mathrm{V}] /[+\mathrm{AGR}]$
PB: COMP: $[-\mathrm{V}] /[-\mathrm{AGR}]$
Pessoa: $[+\mathrm{V}] /[+\mathrm{AGR}]$
Pessoa: $[+\mathrm{V}] /[-\mathrm{AGR}]$
Pessoa: $[-\mathrm{V}] /[-\mathrm{AGR}]$
Tempo: $[-\mathrm{V}] /[+\mathrm{AGR}]$
Tempo: $[-\mathrm{V}] /[-\mathrm{AGR}]$
Tempo: $[+\mathrm{V}] /[+\mathrm{AGR}]$

De acordo com a proposta de Galves $(2000 ; 2001)$, o que possibilita a relação Especificador/Núcleo é a associação de traços-V fortes [+V] e de traços [+AGR]. Considerando essa asserção e o esquema acima, em PE a relação Especificador/Núcleo não vai ser estabelecida em nenhuma das categorias funcionais visto que não há em nenhuma delas traços-V fortes associados a traços [+AGR]. Logo, essa ausência da associação de traços-V a traços-AGR nas categorias funcionais COMP, P e T licencia apenas a ênclise em PE. Em PB, por sua vez, há traços-V fortes associados a traços [+AGR] em T, condição em que a próclise é licenciada.

A incompatibilidade da ênclise com a relação de Especificador/Núcleo fica mais clara nas derivações abaixo, retiradas de Galves (2001, p. 230):
(4) $\mathrm{XP}[\mathrm{CP} V-\mathrm{cl}[\mathrm{IP} \ldots]]$ - relação $\mathrm{Esp} / \mathrm{N}$
(5) $[\mathrm{CP} \mathrm{XP}$ cl-V $[\mathrm{IP} . .]$.$] + relação Esp/N, a próclise é derivada$
(6) *[CP XP V-cl [IP ...] ] + relação Esp/N, a ênclise é bloqueada

em (4), a ênclise é licita apenas pelo fato de o elemento [XP] que antecede o verbo ser realizado fora dos domínios de CP; em (5), a relação Especificador/Núcleo é estabelecida por meio da presença de um elemento $[\mathrm{XP}]$ na posição de especificador de CP, e o 
padrão é a próclise; em (6) há a uma estrutura em que a ênclise não pode ser licenciada quando a relação Especificador/Núcleo é estabelecida.

Ainda sobre o esquema de distribuição de traços em COMP, Pessoa e Tempo proposto por Galves, vemos que, em PC, o verbo sobe até COMP, visto que esta é uma característica das línguas-V2, porém, antes de subir a COMP, o verbo passa pela categoria Pessoa em que há presença de traços AGR, licenciando a relação Especificador/Núcleo para esta categoria. Os exemplos abaixo ilustram a forma como se dá a colocação de clíticos em sentenças escritas no século XVIII, retirados de Galves (2001, p.217):

(7) O amigo Pedro Antonio me disse ultimamente que V.M me remetia mais tabaco [...].

(Gusmão)

(8) $\mathrm{O}$ ar parece-me bastante benigno. (marquês do Lavradio)

De acordo com a proposta e Galves, o fato de PC possuir traços $[+\mathrm{V}]$ e traços [+AGR] na categoria Pessoa e de a relação Especificar/Núcleo ser estabelecida na estrutura da sentença, a próclise élicenciada. Contudo, vemos que apesar disso há no exemplo (8) a ocorrência de um caso de ênclise e isso se deve à "disponibilidade de duas posições para o sintagma pré-verbal, sujeito ou não sujeito [na estrutura da sentença]: uma posição interna à oração e uma posição externa à oração". (GALVES, 2001, p. 219). Em (7) há um caso em que o elemento pré-verbal está interno à sentença, logo o padrão de colocação é a próclise; em (8), a ênclise é licenciada pelo fato de o elemento [XP] que antecede o verbo estar em uma posição externa à sentença e o verbo estar alçado a COMP.

Em PE, por sua vez, a única categoria que possui traços- $\mathrm{V}$ fortes $[+\mathrm{V}]$ é a categoria Pessoa e essa não tem traços AGR. Dessa forma, o único padrão possível de colocação de clíticos nesse contexto é a ênclise, como podemos observar em (9).

(9) Paulo viu-me. 
A ênclise é licenciada pois o verbo é alçado à categoria Pessoa e lá não há a relação Especificador/Núcleo devido à ausência de traços [+AGR] associados aos traços-V, logo a ênclise é obrigatória.

Em $\mathrm{PB}$, o verbo não sobe para Pessoa, pois nessa categoria não há traços-V fortes e com isso, o verbo fica na categoria Tempo em que há traços- $\mathrm{V}$ fortes associados a traços [+AGR], licenciando a próclise, conforme (10).

(10) Paulo me viu.

A próclise nesse contexto é licenciada em $\mathrm{PB}$ devido à associação entre traços $[+\mathrm{V}]$ e [+AGR] na categoria Tempo em que a relação Especificador/Núcleo é estabelecida.

A proposta de Galves $(2000 ; 2001)$ explica a colocação de clíticos em sentenças finitas nas gramáticas do português - PC, PE e PB. Nos valeremos na proposta da autora para respaldar nossa análise para a colocação de clíticos em sentenças infinitivas preposicionadas em PB.

\subsection{A proposta de Magro (2005): o estatuto categorial das preposições em português}

A proposta de Magro (2005) para a colocação de clíticos em sentenças infinitivas do PE, tendo em vista dados retirados do corpus CORDIAL-SIN ${ }^{3}$, baseia-se na hipótese de que os elementos que introduzem as orações infinitivas possuem estatutos categoriais diferentes. Magro assume que as preposições possuem dois estatutos: (a) núcleo de um sintagma preposicional (PP), configurando-se como uma verdadeira preposição, e (b) núcleo de um $\mathrm{CP}$, funcionando como um complementizador. Em estruturas derivadas com preposições do primeiro caso, a categoria CP não é projetada, visto que o elemento que está encabeçando a oração infinitiva é a projeção máxima de um núcleo preposicional, de um PP. Já no segundo caso, CP é projetado visto que o seu núcleo está ocupado por uma preposição com estatuto de complementizador, núcleo de CP.

\footnotetext{
${ }^{3}$ O CORDIAL-SIN (Corpus Dialetal com Anotações Sintáticas) é um corpus elaborado desde 1999 pelo Grupo de Estudos de Dialectologia do Centro de Linguística da Universidade de Lisboa. Esse corpus é formado por excertos de fala espontânea ou semi-dirigida, transcritos ortograficamente a partir de gravações de inquéritos dialectais realizados entre os anos 70 e os anos 90 .
} 
Da proposta de Magro (2005), consideremos com mais vagar duas hipóteses centrais: (1) as preposições que favorecem a ênclise e a subida de clítico são as verdadeiras preposições e as preposições que favorecem a próclise e não favorecem a subida de clítico são complementizadores; (2) há duas entradas lexicais em uma só gramática para itens como as preposições: uma entrada para verdadeiras preposições e outra para preposições com função de complementizadores.

Concordaremos, por enquanto, com Magro em relação à primeira hipótese, visto que acreditamos que as verdadeiras preposições podem ser aquelas em que favorecem a colocação enclítica em PE, enquanto as preposições que ocupam o núcleo de COMP favorecem a próclise. Com o objetivo de identificar quais preposições verdadeiras (núcleo de PP) e quais não verdadeiras (núcleo de $\mathrm{CP}$ ), retomaremos os resultados empíricos obtidos por Magro (2005). As preposições em PE que apresentam maior percentual de ênclise são $a$ e $\mathrm{em}$. As demais preposições apresentam-se em sentenças majoritariamente com próclise. Dessa forma, temos como verdadeiras as preposições a e em - núcleos de um PP - e como complementizadoras as preposições de, para, por e sem - núcleos de CP. Diante disso, seguindo a proposta de Magro (2005), a derivação das sentenças com verdadeiras preposições se realizaria como em (11):

(11) $\mathrm{V}_{\text {MAT }}[\mathrm{pp} a / e m[\Sigma \mathrm{P} \Sigma[\mathrm{TP}[\mathrm{T}[\mathrm{Vinf}+\mathrm{T}] \mathrm{cl}]$

A categoria $\Sigma$ não possui nenhum conteúdo lexical e também não é licenciada pela sua relação com CP, o que motivaria a derivação da ênclise. Nesse caso, segundo Magro (2005), a ênclise é o padrão de colocação, sendo derivada no componente morfológico. Isso ocorre devido à presença de uma verdadeira preposição, ou seja, de uma preposição que ocupa o núcleo de PP - " $a / \mathrm{em}$ ", visto que, na ausência de material lexical em $\Sigma \mathrm{P}$, a única forma de legitimar essa categoria é a relação dela com CP. Dessa forma, estando $\mathrm{CP}$ ausente na derivação fica inviável a legitimação de $\Sigma \mathrm{P}$, e, logo, a próclise não é licita pois essa está associada à legitimação de $\Sigma$. Podemos exemplificar os casos de ocorrência com preposição verdadeira e ênclise nas sentenças (12) e (13) retiradas de Magro:

(12) Faz mal ao organismo estar a cozê-lo.

(13) A baleia da em tombar-se de lado e a gente vê que está na hora de morrer. 
Observe-se que a ênclise se dá preferencialmente com as preposições a e em em PE. Sendo esse o padrão de colocação favorecido pelas verdadeiras preposições, entendemos, seguindo a proposta de Magro (2005), que a e em possam ser consideradas verdadeiras preposições em PE. A próclise, por sua vez, é derivada quando a presença de CP na derivação permite que haja relação entre essa categoria e a categoria funcional $\Sigma$. Essa relação ocorre com o movimento de $\Sigma$ para CP. Isso permite a legitimação de $\Sigma$; logo a próclise é o padrão de colocação de clíticos em sentenças, como a representada em (14) e exemplificam os dados de (15) a (18), com a preposições não verdadeiras.

(14) $\mathrm{V}_{\mathrm{MAT}}[\mathrm{CP} d e[\Sigma \mathrm{P} \Sigma[\mathrm{TP}[\mathrm{T} \mathrm{cl}[\mathrm{Vinf}+\mathrm{T}]]$

$$
\begin{gathered}
\text { Movimento de } \\
\Sigma \text { para C }
\end{gathered}
$$

(15) O animal via que não era capaz de me dar saída, voltou-se contra mim.

(16) A cilha tem duas fivelas e depois tem uma correia para se apertar.

(17) Ora, ficaram muito contentes por lhe amostrar a sua casa.

(18) Dizia que andava há não se quantos dias sem se deitar.

Observe-se que as preposições que figuram a próclise são as preposições de, para, por e sem. Magro (2005) mostra que a próclise com essas preposições é muito recorrente, o que a leva a considerar que essas preposições não são verdadeiras preposições em PE, mas estariam associadas a CP.

Não desenvolveremos a segunda hipótese levantada por Magro (2005) neste artigo porque ela não está diretamente associada à proposta que teceremos na próxima seção para a colocação de clíticos em sentenças infinitivas preposicionadas em $\mathrm{PB}$.

\section{Uma proposta para a colocação de clíticos em sentenças infinitivas preposiciona- das nas gramáticas do português}

Nesta seção, apresentaremos uma proposta teórica para explicar como se dá a colocação de clíticos em sentenças infinitivas preposicionada em PB. Essa proposta segue 
aquela delineada em Sena Pereira (2015) e está fundamentada nas propostas de Galves (2000; 2001) e de Magro (2005), brevemente revisadas acima.

Magro (2005) assume que, quando há a ocorrência de uma verdadeira preposição, ou seja, de uma preposição que ocupe o núcleo de um PP, a ênclise é o padrão em PE, visto que a categoria funcional localizada acima de TP não é licenciada nem pela presença de um item lexical nem pela relação dessa categoria com COMP. Na análise, a autora considera que a categoria que se localiza logo acima de TP é a categoria funcional $\Sigma$. A análise toma por base a proposta desenvolvida em Costa e Martins (2003; 2004) que define $\Sigma$ como uma categoria funcional forte responsável pela codificação de aspectos relativos à polaridade e à ênfase. $\mathrm{Na}$ análise aqui proposta, consideraremos que a categoria funcional situada acima de TP é a categoria Pessoa, assim como é proposto por Galves (2000; 2001).

Nesse caso, a ênclise é derivada no componente morfológico, ou seja, o clítico é ligado/adjungido ao verbo morfologicamente, como podemos ver em (19):

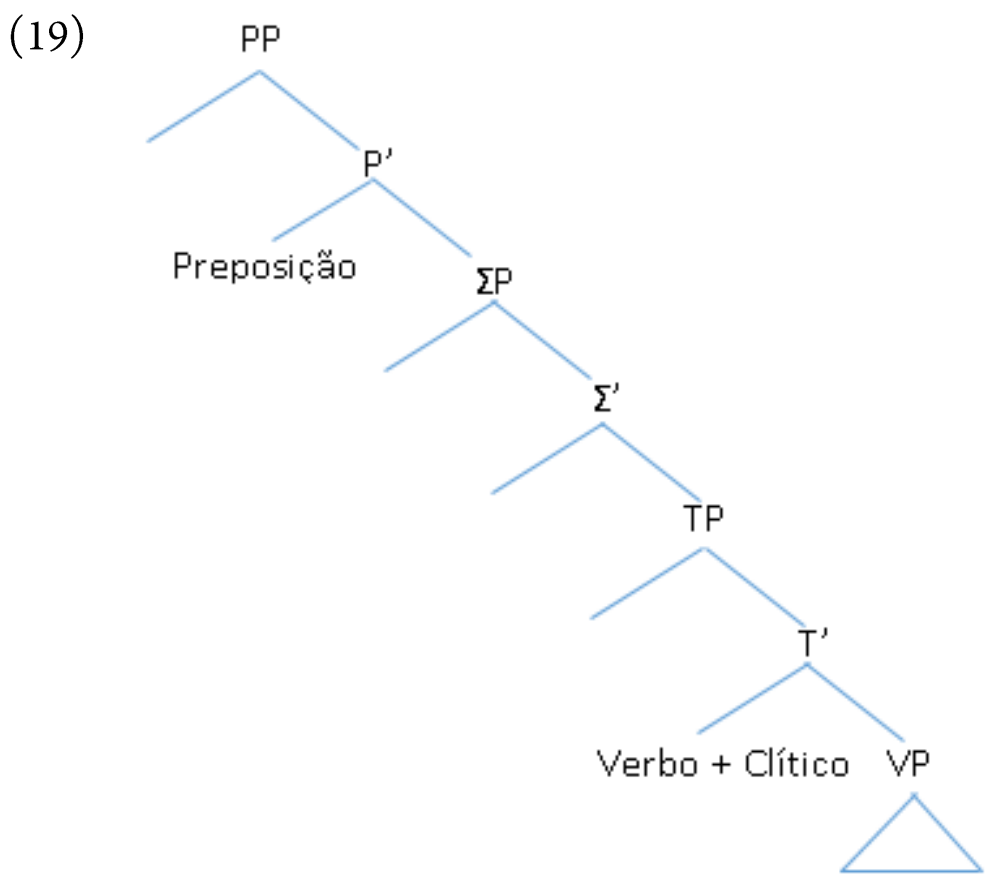

De acordo com Magro, a derivação expressa em (19) obriga a ênclise, pois a categoria funcional $\Sigma$ não é licenciada por não haver material lexical a ela associado e por COMP não estar presente na derivação. A próclise ocorreria em sentenças em que a preposição fosse núcleo de CP. 
Como não consideraremos a categoria funcional $\Sigma$ nesta análise, e sim a categoria Pessoa (como proposto por Galves, 2000; 2001), defendemos que o licenciamento de $\Sigma$ não é significativo para a derivação da próclise ou da ênclise. O que determinará a derivação de uma ou outra colocação do pronome pessoal clítico é a associação de traços- $\mathrm{V}$ fortes aos traços [+AGR] na categoria funcional Pessoa no PB. Nesse caso, a estrutura expressa em (19), tal qual proposta por Magro (2005), passaria, a priori, a ser aquela em (20) em que substituímos $\Sigma$ P por PessP:

(20)

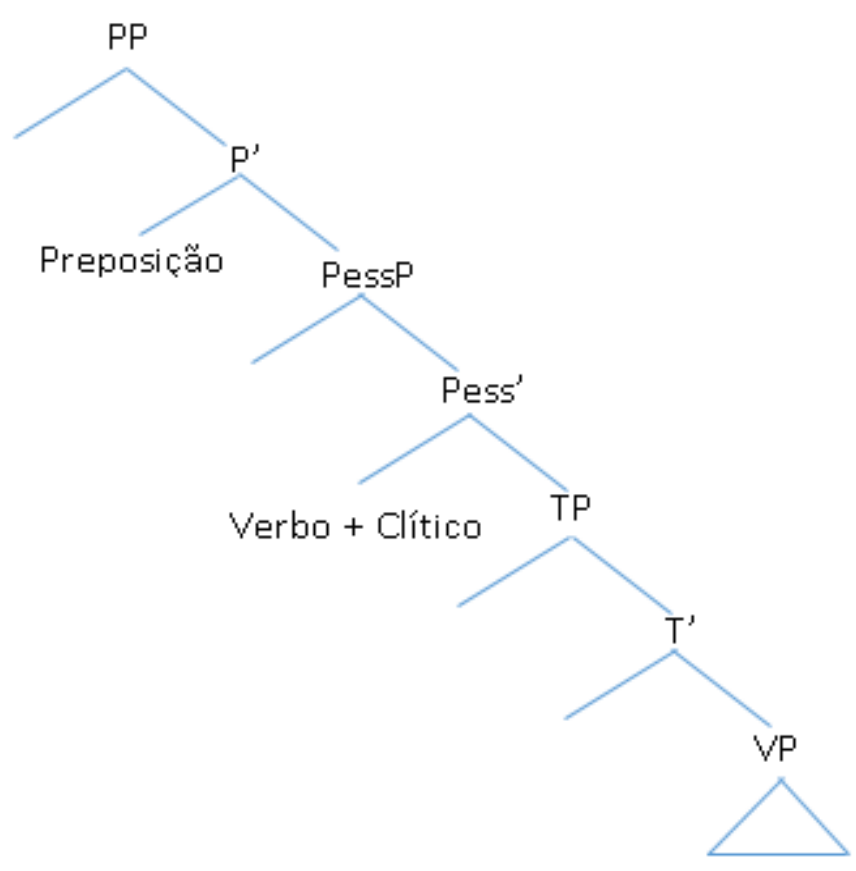

A ocorrência da categoria funcional Pessoa tem em seu núcleo o verbo movido com o clítico adjungido. Note-se que a preposição ocupa o núcleo de um sintagma preposicional, e logo, seguindo a análise de Magro (2005), a presença da preposição em sua posição canônica é um fator que obriga a ocorrência da ênclise em PE. Neste caso, a ênclise será a única opção de colocação do pronome pessoal clítico, conforme já dito, como um processo morfofonológico.

No que se refere ao $\mathrm{PB}$, considerando a relação entre traços- $\mathrm{V}$ e traços-phi para uma derivação como em (20), assumimos aqui que a ocorrência de uma verdadeira preposição na sentença não desencadeia nenhuma mudança na configuração de traços na categoria Pessoa, de forma que tal categoria possui traços do tipo [+V] e [-AGR]. Como 
vimo na proposta de Galves $(2000 ; 2001)$ essa configuração de traços não licencia uma relação de Especificador/Núcleo e a ausência dessa relação permite a derivação da ênclise em sentenças com uma estrutura como em (20).

A proposta que apresentamos aqui para a derivação da próclise em sentenças infinitivas preposicionadas no PB está baseada principalmente na diferença entre preposições verdadeiras e preposições que desempenham a função de complementizador. Defendemos que, em $\mathrm{PB}$, em estruturas em que a preposição ocupa a posição de núcleo de $\mathrm{CP}$, a distribuição de traços $[\mathrm{AGR}]$ e de traços-V ocorre como no esquema a seguir, adaptado da proposta de Galves $(2000 ; 2001):^{4}$

\author{
PE: COMP: $-\mathrm{V} /+\mathrm{AGR}$ \\ Pessoa: $+\mathrm{V} /+A G R$ \\ Tempo: -V/-AGR
}

\author{
PB: COMP: -V/-AGR \\ Pessoa: $+V /$-AGR \\ Tempo: $+\mathrm{V} /+\mathrm{AGR}$
}

Por não ser objetivo deste artigo, não entraremos em detalhes da proposta para o PE.

Em PB, a mudança de $[-\mathrm{V}]$ para $[+\mathrm{V}]$ em Pessoa nas sentenças infinitivas preposicionadas $^{5}$, devido à presença da preposição em núcleo de $\mathrm{CP}$, faz com que o verbo se movimente para o núcleo de PessP. Com isso, o verbo estaria em uma categoria em que os traços [AGR] não estão associados ao traço-V forte; ou seja, temos uma configuração traçual de $[+\mathrm{V} ;-\mathrm{AGR}]$, conforme esquema acima. Logo, apenas a ênclise é licenciada como recurso de um processo morfofonológico. Neste ponto, vemos que a previsão de próclise feita por Magro (2005) para as sentenças em que a preposição tem o estatuto categorial de complementizador em PE não é repetida em PB devido a mudança na valoração dos traços-V e dos traços-AGR em PB. Com isso, nas sentenças em que a preposição ocupa o núcleo de $\mathrm{CP}$, propomos que a derivação da ênclise ocorre como em (21) a seguir:

\footnotetext{
${ }^{4}$ A proposta de Galves $(2000 ; 2001)$ trata da colocação de clíticos em sentenças finitas, porém, neste artigo, adotamos também essa proposta para explicar a colocação de clíticos em sentenças infinitivas. Entendemos que a categoria Pessoa está presente nas construções com infinitivo flexionado no PB.

${ }^{5}$ A motivação dessa mudança nas infinitivas preposicionadas fica como uma discussão a ser feita em outro momento. Não entraremos em detalhes neste artigo.
} 
(21)

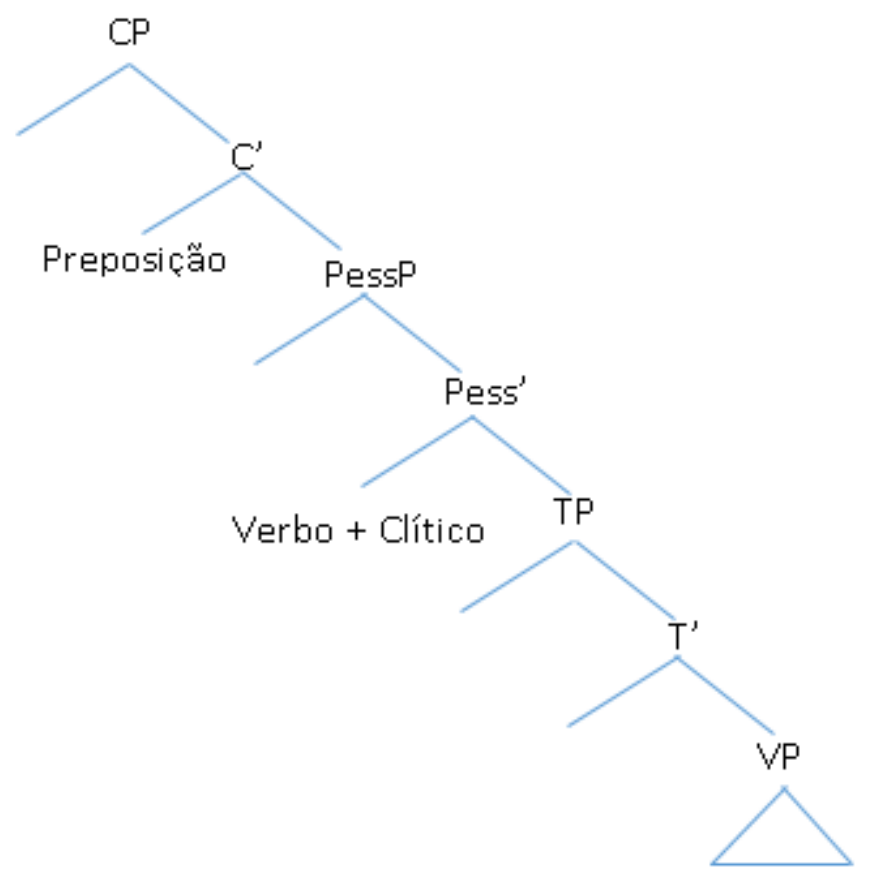

É a presença da preposição no núcleo de $\mathrm{CP}$, ou seja, de uma preposição com estatuto de complementizador, que força a colocação enclítica em sentenças infinitivas devido à mudança no valor do traço $[-\mathrm{V}]$ para $[+\mathrm{V}]$ na categoria Pessoa em PB. Ou seja: a configuração traçual estabelecida pela presença de uma preposição com o estatuto de complementizador inibe a relação Especificador/Núcleo e licencia a ênclise em PessP no PB.

Observe-se que a proposta desenvolvida por Sena Pereira (2015) diverge do que é proposto por Magro (2005) ao sugerir que o estatuto categorial das preposições que está associado à derivação da ênclise em PB é, justamente, aquele em que as preposições são núcleos de CP. Para Magro, esse contexto licenciaria a próclise em PE, mas o que vemos em PB, segundo Sena Pereira, é o licenciamento da ênclise devido à configuração traçual motivada pela ocorrência de uma preposição com função de complementizador.

A mudança dos valores dos traços- $\mathrm{V}$ e dos traços-AGR não ocorre quando a preposição ocupa o núcleo de um PP, como podemos ver em (22): 
(22)

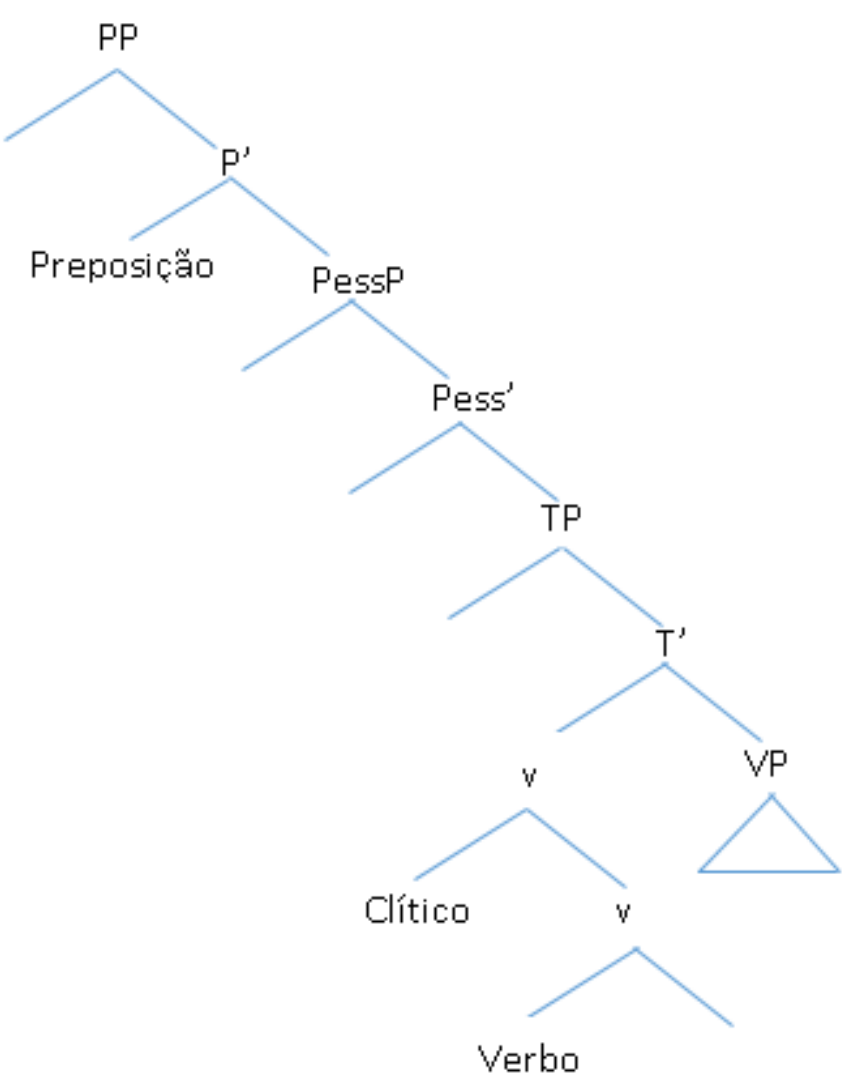

A preposição ocupa sua posição canônica que é a posição correspondente ao núcleo do sintagma preposicional. Nesse caso, não há mudança de valores quanto aos traços-V em PessP. Com isso, a derivação da próclise se dá de forma semelhante à ocorrida com as sentenças finitas, ou seja, o verbo não alcança categorias mais altas que Tempo em $\mathrm{PB}$, mantendo-se nos domínios de TP onde há traços-V fortes e traços [+AGR]. Isso torna a ênclise ilícita nesse contexto.

Diante do que expomos até agora, vemos que a proposta que estamos desenvolvendo nos permite identificar dois tipos de movimentos do verbo em PB: (a) um movimento do verbo para PessP decorrente da presença de uma preposição não verdadeira; $\mathrm{e}$ (b) um movimento do verbo para TP decorrente da presença de uma verdadeira preposição.

Com isso, vemos que a hipótese de que as preposições que favorecem a ênclise são as verdadeiras preposições e as que favorecem a próclise têm o estatuto de complementizador não contribuem para a nossa proposta, visto que essas diretrizes são compatíveis apenas com o PE. As mudanças nos valores dos traços V-fortes e traços-phi mostram que, 
para o $\mathrm{PB}$, as preposições verdadeiras favorecem a próclise, seguindo assim a tendência proclitizadora característica de PB. Por outro lado, as preposições com estatuto de complementizador favorecem a ênclise, visto que, nesse contexto, a categoria funcional Pessoa passaria a ter traços $[+\mathrm{V}]$, forçando o verbo a se movimentar para os domínios dessa categoria em que não há traços de AGR associados aos traços verbais. Isso torna a ênclise lícita nesse contexto em PB. ${ }^{6}$

Essa análise mostra que a colocação de clíticos está associada às diferentes valorações dos traços-phi e V-fortes e às diferentes marcações categoriais das preposições em PB. Vemos, também, com essa análise, que PB se diferencia de PE tanto no que se refere aos valores dos traços AGR e V na categoria Pessoa como na marcação do estatuto categorial das preposições.

\section{Considerações finais}

A proposta apresentada neste artigo, baseada em Sena Pereira (2015) busca uma explicação para a colocação de clíticos em sentenças infinitivas preposicionadas em PB. A maioria das propostas anteriormente desenvolvidas para explicar como se dá a colocação de clítico em sentenças do português não contemplam, ou não aprofundam, de maneira particularizada, a ordenação do pronome átono em sentenças infinitivas. Vale ressaltar que Sena Pereira (2015) não propõe uma explicação isolada para a colocação de clítico em sentenças infinitivas preposicionadas. A proposta está diretamente relacionada a de Galves $(2000 ; 2001)$ que explica a colocação de clíticos em sentenças finitas. A diferença presente na proposta de Sena Pereira (2015) se baseia na mudança da valoração dos traços-phi e traços $\mathrm{V}$-fortes diante dos estatutos categoriais que as preposições podem assumir na derivação em PB.

Diante do que foi exposto, parece que em $\mathrm{PB}$ as preposições que funcionam como complementizadores, ou seja, ocupam o núcleo de $\mathrm{CP}$, ocasionam uma mudança no valor dos traços pertencentes à categoria funcional Pessoa. Dessa forma, em PessP, há a ocorrência de traços $[+\mathrm{V}]$ associados aos traços $[+\mathrm{AGR}]$, o que ocasionaria a próclise nesse contexto. Por outro lado, a presença da preposição em núcleo de PP ocasiona uma

\footnotetext{
${ }^{6}$ Admitimos que não explicamos aqui a que se devem essas diferenças em relação ao estatuto das preposições e a colocação pronominal em PE e em PB. Esse é um ponto em aberto que precisa ser investigado em outro momento.
} 
mudança no valor dos traços- $\mathrm{V}$ na categoria PessP, de $[-\mathrm{V}]$ para $[+\mathrm{V}]$ e essa mudança motivaria a ênclise, pois o verbo seria alçado para a posição de núcleo de PessP e não estaria associado a traços AGR, logo a ênclise seria lícita.

Por fim, vale ressaltar a importância deste estudo que traz a discussão acerca da ordenação de pronomes clíticos em um contexto específico. Ressaltamos, no entanto, que a colocação de clíticos em sentenças infinitivas preposicionadas em português configura-se em um objeto de estudo que ainda carece de muita pesquisa.

\section{Bibliografia}

CARNEIRO, Z. Cartas brasileiras (1809-1904): um estudo linguístico-filológico.2005. Tese (Doutorado em Linguística) - Instituto de Estudos da Linguagem, Unicamp, Campinas, 2005.

CHOMSKY, N. O Conhecimento da Língua: Sua Natureza, Origem e Uso. Porto: Caminho, 1994.

COSTA, J.; MARTINS, A. M. Clitic placement across grammar components. Comunicação apresentada no Going Romance. Nijmegen: Nijmegen University, 2003.

. What is a strong functional head? Comunicação apresentada no Lisbon Workshop on Alternative Views on the Functional Domain. Lisboa: Universidade Nova de Lisboa, 2004.

CYRINO, S. M. L. Mudança sintática. In: MARTINS, M. A.; TAVARES, M. A. (Org.). História do português brasileiro no Rio Grande do Norte: análise linguística e textual da correspondência de Luís da Câmara Cascudo a Mário de Andrade - 1924 a 1944. - Natal, RN: EDUFRN, 2012.

. Mudança sintática e português brasileiro. In: CASTILHO, Ataliba; TORRES MORAIS, Maria Aparecida; LOPES, Ruth; CYRINO, Sonia Maria Lazzarini (Org.). Descrição, história e aquisição do Português Brasileiro. Campinas: Pontes, 2007.

GALVEZ, C. A língua das caravelas: periodização do português europeu e origem do português brasileiro. In: CASTILHO, A; TORRE MORAIS, M. A.; LOPES, R; CYRINO, S. (Org.). Descrição, história e aquisição do Português brasileiro. Campinas: Pontes, 2007.

. Agreement, predication end pronouns in the history of portuguese. In: COSTA, J. Portuguese Syntax: New comparative studies. New York: Oxford University press, 2000.

. Ensaios sobre as gramáticas do português. Campinas: Editora da Unicamp,

2001. 
GALVES, C; NAMIUTI, C; PAIXÃO DE SOUSA, M. C. Novas perspectivas para antigas questões: revisitando a periodização da língua portuguesa. In: ENDRUSCHAT, A.; KEMMLER, R.; SCHÄFER-PRIEB, B. (Org.) Grammatische Structuren des Europäischen Portugiesisch. Turbigen: Calapinus, 2006.

GALVES, C.; CARNEIRO, Z. Variação e Gramática: colocação de clíticos na história do português brasileiro. Revista Estudos Linguísticos, Belo Horizonte, 2010.

CYRINO, S. (Org.). Descrição, história e aquisição do português brasileiro. Campinas: Pontes, 2007.

KROCH, A. Reflexes of Grammar in Patterns of Language Change. Language Variations and Change, v. 1, p. 199-244, 1989.

. Syntactic Change. In. Baltin \& Collins (eds.). The handbook of contemporary syntactic theory. Massachusetts: Blackwell, 2001.

. Mudança sintática. Tradução de Silvia Cavalcante. 2003. Disponível em: http://www.ling.upenn.edu/ kroch.

LABOV, W. Padrões sociolinguísticos. São Paulo: Parábola Editorial, 2008

LIGHTFOOT, D. The development of language: Acquisition, change, and evolution. Malden, MA: Blackwell, 1999.

. Principles of diachronic syntax. Cambridge: Cambridge University Press, 1979.

. Grammatical Approaches to Syntactic Change. In: JOSEPH, B. D.; JANDA,

R. D. (Org.). The handbook of historical linguistics. Hoboken: Blackwell, 2003.

LUCCHESI, D. Sistema, mudança e linguagem: um percurso na história da linguística moderna. São Paulo: Parábola, 2004.

MAGRO, C. Introdutores de orações infinitivas: o que diz a sintaxe dos clíticos. Associação Portuguesa de Linguística, 2005. Disponível em:

http://www.clul.ul.pt/files/catarina_magro/trabalho_ID.pdf.

MATEUS, M. H. M; BRITO, A. M; DUARTE, I; FARIA, I. H. Gramática da língua portuguesa. Lisboa: Caminho, 2003.

MARTINS, A.M. Clíticos na história do português. Tese (Doutorado em Linguística) Faculdade de Letras, Universidade de Lisboa, Lisboa, 1994.

. Posição dos pronomes clíticos pessoais. In: RAPOSO, E; BACELAR,

M.F; MOTA, M. A; SEGURA, L.; MENDES, A. (Org.). Gramática do português. Lisboa: Fundação Calouste Gulbenkia, 2013.

MARTINS, M. A. Gramática ou gramáticas do português brasileiro? O problema da implementação na mudança sintática. Língua e Instrumentos Linguísticos, v. 32, p. 9-27, 2013. 
MARTINS, M. A. Competição de gramáticas do português na escrita catarinense dos séculos 19 e 20. 2009. Tese (Doutorado em Linguística) - Programa de Pós-Graduação em Linguística, Universidade Federal de Santa Catarina, Florianópolis, 2009.

. A colocação de pronomes clíticos na escrita brasileira: para o estudo das gramáticas do Português. Natal: EDUFRN, 2012.

MARTINS, M. A.; COELHO, I. L.; CAVALCANTE, S. R. de O. Variação e Gerativismo. In: MARTINS, M. A; ABRAÇADO, J. Mapeamento sociolinguístico do português brasileiro. São Paulo: contexto, 2015. (No prelo).

NAMIUTI-TEMPONI, C. Uma reflexão gerativista sobre a dimensão dinâmica de mudanças sintáticas na diacrônia do português. In: XVI Congreso Internacional de la Asociación de Lingüistica y Filología de la América Latina (ALFAL), Alcalá de Henares. Obras Coletivas de Humanidades 28. Actas del XVI Congresso Internacional de la ALFAL. Alcalá de Henares: UAH: Universidade de Alcalá de Henares, 2011.

PAIXÃO DE SOUSA, M. C. Língua barroca: sintaxe e história do português nos 1600. Campinas. Unicamp, 2004.

PAGOTTO, E. A posição dos clíticos em português: um estudo diacrônico. Dissertação (Mestrado em Linguística) - Instituto de Estudos da Linguagem, Universidade Estadual de Campinas, 1992.

POLLOCK, J. Verv Movement, Universal Grammar, and the Structure IP. The MIT press, 1989. Disponível em: http://babel.ucsc.edu/ hank/pollock.pdf.

ROBINSON, J.; LAWRENCE, H.; TAGLIAMONTE, S. GoldVarb: a multivariate analysis application for Windows. Department of Language an Linguistic Science: University of York, 2001. Disponível em:

http://www.york.ac.uk/depts/lang/webstuff/goldvarb/.

SHEI, A. A colocação pronominal do português brasileiro: a língua literária contemporânea. São Paulo: Humanitas/FFLCH/USP, 2003.

TARAllO, F. L. A pesquisa sociolinguística. 8. ed. São Paulo: Ática, 2007. (Princípios 9).

WEINREICH, U.; LABOV, W.; HERZOG, M. Empirical foundations for a theory of language change. In: LEHMANN, W. P.; MALKIEL, Y. (Ed.). Directions for historical linguistics. Austin: University of Texas Press, 1968.

. Fundamentos empíricos para uma teoria da mudança linguística. Tradução de Marcos Bagno. São Paulo: Parábola, 2006.

Data de submissão na OJS: 18/07/2016

Data de aceite registrado na OJS: 16/08/2016 